\title{
BACHARÉIS DOCENTES: A FORMAÇÃO DE PROFESSORES NÃO LICENCIADOS
}

\author{
Marizete Bortolanza Spessatto ${ }^{\mathrm{i}}$ \\ Instituto Federal de Educação, Ciência e Tecnologia de Santa Catarina - IFSC (Brasil) \\ Celso João Carminati \\ Universidade do Estado de Santa Catarina - UDESC (Brasil)
}

\begin{abstract}
Resumo: Este artigo visa contribuir com as reflexões acerca da formação pedagógica para docentes com trajetórias acadêmicas e profissionais anteriores distantes do espaço da sala de aula. O foco da análise está na carreira da Educação Básica, Técnica e Tecnológica - EPT que, no Brasil, passou por grande expansão nos últimos dez anos. Ao analisar os depoimentos de vinte docentes do Instituto Federal de Santa Catarina, visamos identificar as trajetórias profissionais e a formação acadêmica desses sujeitos e contribuir com o debate sobre a formação pedagógica para a profissionalização docente (Pimenta e Anastasiou, 2002). A análise permitiu confirmar a grande atração exercida por concursos públicos sobre as escolhas profissionais de bacharéis de diferentes áreas que acabam se tornando professores. Essa situação evidencia a importância de políticas públicas que garantam a formação pedagógica desses profissionais, conforme alertam, entre outros, Moura (2008) e Machado (2008), considerando-se as especificidades do processo ensino aprendizagem.
\end{abstract}

Palavras-chave: Docência. Educação Profissional e Tecnológica. Formação Pedagógica.

\section{TEACHING BACHELORS: THE TRAINING OF UNLEADED TEACHERS}

\begin{abstract}
This article aims to contribute with the reflections about the pedagogical formation for teachers with previous academic and professional trajectories far from the space of the classroom. The focus of the analysis is on the career of Basic, Technical and Technological Education - EPT, which, in Brazil, has undergone great expansion in the last ten years. When analyzing the testimonies of twenty professors of the Instituto Federal de Santa Catarina, we aimed to identify the professional trajectories and the academic formation of these subjects to contribute with the debate about the pedagogical formation for the teaching professionalization (Pimenta and Anastasiou, 2002). The analysis allows to confirm the great attraction of public examinations about the professional choices of bachelors from different areas that end up becoming teachers. This situation highlights the importance of public policies that guarantee the pedagogical training of professionals, according to, among others, Moura (2008) and Machado (2008), considering the specificities of the learning process.
\end{abstract}

Keywords: Teaching. Professional and Technological Education. Pedagogical formation. 


\title{
LICENCIADOS DOCENTES: LA FORMACIÓN DE PROFESORES SIN CAPACITACIÓN EN DOCENCIA
}

\begin{abstract}
Resumen: Este artículo pretende contribuir a la reflexión sobre la formación pedagógica para profesores que poseen trayectorias académicas y profesionales no relacionadas con el ambiente de clase. La atención del análisis está puesta en el contexto de Educación Básica, Técnica y Tecnológica - EPT que, en Brasil, se ha expandido considerablemente en los últimos diez años. Al analizar las declaraciones de veinte profesores del Instituto Federal de Santa Catarina, se buscó identificar las trayectorias profesionales y la formación académica de esos sujetos para contribuir con el debate sobre la capacitación pedagógica para la profesionalización docente (Pimenta e Anastasiou, 2002). El análisis permite confirmar que los concursos públicos son un gran atractivo para las elecciones profesionales de licenciados de distintas áreas llevándolos a convertirse en profesores. Ese hecho llama la atención para la importancia de proponerse políticas públicas que garanticen la capacitación pedagógica de esos licenciados, como explica, entre otros, Moura (2008) y Machado (2008), considerándose las especificidades del proceso de enseñanza y aprendizaje.
\end{abstract}

Palabras-clave: Docencia. Educación Profesional y Tecnológica. Capacitación Pedagógica.

\section{Introdução}

\section{Os desafios da formação de professores na EPT}

Ser professor ou estar professor? Em um cenário de expansão de concursos públicos, sobretudo na última década, a profissão docente passou a atrair a atenção de profissionais de diferentes áreas, muitos dos quais com formações iniciais que preparam para um exercício profissional bem distante do espaço das salas de aula. Esse cenário traz à tona uma discussão que não é recente, mas é mal resolvida: a formação continuada de professores. Se já é complexo pela falta de políticas, de valorização da carreira e de investimentos públicos, o tema se torna ainda mais difícil quando envolve um público tão heterogêneo quanto o de profissionais que, em geral, não têm formação específica para a docência e é atraído para a educação via concursos públicos para as carreiras do magistério superior e, mais recentemente, da Educação Básica, Técnica e Tecnológica - EPT que passou por grande expansão nos últimos dez anos e é o foco deste trabalho.

"Não escolhi nada do que sou. Fui escolhido pela EPT", afirma o professor $(\mathrm{P} 6)^{\mathrm{ii}}$, ao falar sobre sua trajetória profissional. Com ingresso no mundo do trabalho ainda na adolescência, passando pela agricultura, construção civil e pela indústria, o bacharel na área da Engenharia afirma que fez concurso público para o cargo que hoje ocupa 'pensando na velhice'. Essa foi a razão de seu ingresso na docência da rede EPT, em 2013. A afirmação descreve a trajetória de um professor do Instituto Federal de Santa Catarina, cujo depoimento foi coletado para a realização deste trabalho. Ele é um dentre os milhares de professores/servidores contratados nos últimos anos, com a expansão da EPT no Brasil. Se, de 1909, ano de implantação das Escolas de Aprendizes Artífices, que estão na origem da rede, até 2002, foram construídas 140 escolas técnicas no país, a partir daí o crescimento foi meteórico: entre 2003 e 2016, o Ministério da Educação abriu mais de 500 novas unidades referentes ao plano de expansão da Educação Profissional, totalizando 644 campi hoje em funcionamento (Brasil, 2016a). Com isso, as oportunidades de trabalho foram significativas: 
... com a ampliação do número de alunos, da oferta de cursos, de novas unidades de ensino e da infraestrutura da Rede Federal, fez-se necessária a ampliação do número de servidores no âmbito da educação profissional, passando o quadro de pessoal da RFEPCT de 36.005 em 2010 para 61.298 em 2015, sendo 33.036 docentes e 28.262 técnico-administrativos em educação (TAE), tendo um aumento percentual na ordem de 70\%. (Brasil, 2016b).

Esse aumento na oferta de vagas para estudantes de diferentes perfis assegura formação inicial e continuada, cursos de Educação de Jovens e Adultos integrados à Educação Profissional e Tecnológica, Ensino Médio integrado à Educação Profissionaliii, graduação e pós-graduação às mais distantes localidades brasileiras. É uma formação gratuita, com uma reconhecida infraestrutura (a maioria dos prédios são novos) que chega a pequenas cidades do interior, historicamente distantes das instituições públicas de ensino das áreas profissionalizantes e de nível superior.

Se, por um lado, o crescimento da rede oportuniza o acesso à sala de aula de diferentes níveis e modalidades de ensino para um expressivo número de novos estudantes, como mostram os dados apresentados, por outro, também atrai para esse mesmo espaço profissionais que, até então, não vislumbravam na docência um caminho de atuação no mundo do trabalho. "Achei uma boa oportunidade, já que as condições de trabalho em uma indústria muitas vezes são ingratas e severas e a docência tem um cenário realizador e mais tranquilo", conta o professor (P8), ingressante na rede por concurso em 2013, que tem trajetória na área da indústria metal mecânica. "Não pensava em atuar especificamente nesse segmento, fazia concurso em áreas distintas", diz a servidora (T24)iv, reforçando a ideia de que atuar na Educação acaba se tornando uma opção de trabalho para quem apostou na segurança e estabilidade do serviço público e se sentiu atraído pelos concursos abertos nos últimos anos. "Tinha apenas mais dois anos de bolsa [Doutorado] e então decidi fazer concursos para adquirir experiência. Passei no primeiro que fiz", afirma o professor (P8).

Esse percurso do bacharelado à sala de aula traz para a Educação conhecimentos ligados à trajetória acadêmica desses sujeitos, mas deixa uma lacuna que precisa ser preenchida. O caminho, acreditamos, passa pela formação continuada, voltada aos aspectos pedagógicos da docência. Ao tratar sobre o tema, Pimenta e Anastasiou (2002) afirmam que o ponto de partida deve ser assumir o exercício do magistério como uma categoria profissional. "Uma ação profissional competente é diferente de uma ação resultante de uma ocupação, emprego ou bico", afirmam as autoras (2002, p. 196 grifos nossos). Essa profissionalização passa pela formação pedagógica para o trabalho em sala de aula, sobretudo quando esta não faz parte do percurso formativo desses profissionais, como é o caso aqui em análise. Muitos autores têm defendido que as formações continuadas de professores precisam considerar a ampliação dos domínios teóricos e conceituais das suas áreas de formação inicial, mas também as "... práticas inovadoras realizadas e analisadas, oferecendo repertório para repensar as políticas e práticas vigentes." (Gatti, 2012, p. 439).

André (2002, p. 172) ressalta aspectos da formação continuada que não podem ser ignorados em qualquer proposta nessa direção, tais como: “... as estratégias de formação continuada propostas de forma vertical, como cursos, seminários, vivências, 
etc"; a discussão sobre "... a identidade profissional do professor e sua construção como sujeito historicamente situado e, nessa construção, a mobilização dos saberes da docência (saberes da experiência, saberes científicos e saberes pedagógicos)" (André, 2002, p. 174).

Concorda-se, ainda, com Alves (apud André, 2002, p. 174) quando aponta que o conceito de capacitação docente deve contemplar:

1)a socialização do conhecimento produzido pela humanidade; 2) as diferentes áreas de atuação; 3) a relação ação-reflexão-ação; 4) o envolvimento do professor em planos sistemáticos de estudo individual ou coletivo; 5) as necessidades concretas da escola e dos seus profissionais; 6) a valorização da experiência do profissional. Mas, também: 7) a continuidade e a amplitude das ações empreendidas; 8) a explicitação das diferentes políticas para a educação pública; 9) o compromisso com a mudança; 10) o trabalho coletivo;11) a associação com a pesquisa científica desenvolvida em diferentes campos do saber.

Quanto à formação de professores para a Educação Profissional e Tecnológica, Viella e Santos (2015, p. 814) questionam as poucas ações voltadas à formação docente na rede, considerando a necessidade desta diante da heterogeneidade não só das trajetórias de formação dos professores, mas também do perfil do público atendido. A Lei $N^{\circ}$ 11.892, de 29 de dezembro de 2008, que institui a Rede Federal de Educação Profissional, Científica e Tecnológica e cria os Institutos Federais de Educação, Ciência e Tecnologia, em seu Art.2o, define-os como “... instituições de educação superior, básica e profissional, pluricurriculares e multicampi, especializadas na oferta de educação profissional e tecnológica nas diferentes modalidades de ensino, com base na conjugação de conhecimentos técnicos e tecnológicos com as suas práticas pedagógicas.” Dessa forma, as autoras destacam ficar clara “... a complexa missão que lhes cabe, especialmente em relação à abrangência das propostas formativas. Ao mesmo tempo em que conjuga níveis e modalidades de ensino diferenciados, coloca em cena um público-alvo também muito heterogêneo", tomando o cuidado para "... não reduzir a formação (dos sujeitos que passam pela EPT) ao conhecimento tácito". (Viella e Santos, 2015, p. 811).

A falta de políticas de formação docente para os professores da EPT e de continuidade para aquelas que são implantadas não são questões novas ${ }^{\mathrm{v}}$. Fazem parte, segundo Machado (2008), do histórico da rede. Ao longo do tempo, na atuação docente na EPT, consolidou-se um lema: “... para ensinar basta saber fazer.” (Pasquali, Vieira e Vieira, 2015, p. 26).

A situação é vista com preocupação pelos pesquisadores da área. Machado (2008, p. 15) enfatiza: "A carência de pessoal docente qualificado tem se constituído num dos pontos nevrálgicos mais importantes que estrangulam a expansão da educação profissional no país". Quando se fala em qualificação, no caso aqui em análise, não se trata da titulação acadêmica desses profissionais, já que, dos professores da rede, 52\% têm cursos de Mestrado; 17\%, Doutorado; e 2\%, Pós-doutorado (Carvalho e Souza, 2014), dados que não se diferenciam muito do perfil dos sujeitos que constituem o corpus de análise deste artigo, como mostraremos na sequência. Trata-se da ausência de uma formação pedagógica na trajetória acadêmica desses docentes. Essa situação ocorre 
em um cenário em que as bases para uma Política Nacional de EPT (2008), no seu Eixo 4, estabelecem diretrizes para a formação dos profissionais da EPT:

A formação dos profissionais da EPT dar-se-á em caráter inicial e continuado. Nesse sentido, torna-se essencial a oferta de Licenciaturas para EPT e de cursos em nível de pós-graduação lato e stricto sensu. $\mathrm{Na}$ perspectiva do decreto $\mathrm{n}$. 5154/04, é preciso rever a formação de professores aproximando e articulando campos do conhecimento de formação profissional. (Pacheco, 2008, p. 06).

Mesmo com essas orientações legais, Machado (2008) destaca que as ofertas formativas para os docentes da rede são muito reduzidas e nem sempre atendem a todos os perfis dos profissionais da carreira. Em pesquisa que trata sobre o tema, Burnier (2006, p. 12) afirma que os professores “... muito embora reconheçam a importância da qualificação, como docentes não se colocam a questão qualificar-se ou não." Sem uma oferta de formação pedagógica sistematizada, capaz de atrair esse público e contribuir para que o professor possa refletir sobre a própria prática, Oliveira Jr. (2008 apud Carvalho e Souza, 2014, p. 866) descreve que alguns professores do ensino técnico buscam espontaneamente os cursos de licenciatura em Pedagogia, "mas acabam se frustrando, pois, nesses cursos, via de regra, os conteúdos estão restritos ao domínio da formação de professores para o ensino fundamental. Em geral, nem uma linha é escrita, nenhum exemplo é dado, no campo da educação profissional."

Para Moura (2008, p. 31), é preciso considerar dois grandes eixos da formação dos docentes da EPT. O primeiro está relacionado com a área de conhecimento específica, adquirida na graduação, cujo aprofundamento é estratégico e deve ocorrer por meio dos programas de pós-graduação, principalmente stricto sensu, oferecidos pelas instituições de educação superior nacionais e ou estrangeiras. $\mathrm{O}$ outro eixo referese à formação didático-político pedagógica e às especificidades das áreas de formação profissional que compõem a esfera da EPT.

Neste artigo, procuramos, ao analisar as 'vozes' (cf. Burnier, 2006) de docentes da rede, contribuir com o debate acerca das razões para o ingresso na profissão docente e do percurso e necessidades de formação pedagógica desses profissionais. Parte-se, assim como o faz Burnier (2006, p. 04), do pressuposto de que seja preciso identificar projetos e percursos formativos desses sujeitos para sinalizar "pistas para a construção de políticas públicas e de projetos pedagógicos de formação de docentes para essa modalidade de ensino." Ao articularmos as falas dos sujeitos ouvidos neste trabalho com os resultados de pesquisas sobre o tema, reforça-se a necessidade de se efetivarem políticas públicas contínuas nessa direção. Nesse percurso de análise, busca-se identificar as trajetórias profissionais anteriores à docência, a formação acadêmica e as dificuldades indicadas por eles pela falta de formação pedagógica para a docência, considerando-se, inclusive, as especificidades da Educação Profissional e Tecnológica. 
Método

\section{Os sujeitos da pesquisa e as motivações para ingresso e para a formação continuada na docência em EPT}

Tendo como proposito ampliar as reflexões acerca da formação continuada de professores, sobretudo daqueles que vêm de trajetórias acadêmicas que não incluem a formação pedagógica, este trabalho faz uso da pesquisa exploratória, cujo desenvolvimento visa “... levantar informações sobre um determinado objeto, delimitando assim um campo de trabalho, mapeando as condições de manifestação desse objeto" (Severino, 2007, p. 123). Ainda, vincula-se aos estudos de abordagem qualitativa. Esses, de acordo com André (2013),

... se fundamentam numa perspectiva que concebe o conhecimento como um processo socialmente construído pelos sujeitos nas suas interações cotidianas, enquanto atuam na realidade, transformando-a e sendo por ela transformados. Assim, o mundo do sujeito, os significados que atribui às suas experiências cotidianas, sua linguagem, suas produções culturais e suas formas de interações sociais constituem os núcleos centrais de preocupação dos pesquisadores. (André, 2013, p. 97).

Quanto ao grupo em estudo, uma trajetória profissional e acadêmica diversificada marca o perfil dos docentes da rede EPT. A heterogeneidade das ofertas de cursos atrai para o espaço da sala de aula profissionais oriundos de diferentes campos do conhecimento. As características dos sujeitos deste trabalho não fogem a essa regra. Eles fazem parte de duas, das cinco turmas abertas pelo IFSC na especialização em Formação Pedagógica para a Docência na EPT, em 2015. A abertura do curso foi incentivada pelo Ministério da Educação, via Secretaria de Educação Profissional e Tecnológica, que divulgou o projeto pedagógico e abriu edital para candidaturas de dez institutos da rede selecionados por adesão à oferta, tendo como público-alvo do curso os docentes que não possuíam curso de licenciatura, visando atender a cerca de 900 professores nessas condições (Brasil, 2016b).

A especialização fez parte do Plano de Formação de Servidores da Rede Federal - PLAFOR, implementado em 2013, considerando:

... a necessidade de preparar os recém-chegados ao serviço público, e especialmente na Educação Profissional e Tecnológica (EPT), e capacitar aos servidores remanescentes visando o fortalecimento e aprimoramento das competências do servidor público para atuar, promover e proporcionar o desenvolvimento de trabalhos com qualidade, atendendo às demandas e propiciando um diferencial no serviço prestado à sociedade no âmbito da RFEPCT. (Brasil, 2016b, p. 1).

O Instituto Federal de Santa Catarina aderiu à proposta e abriu 140 vagas em cinco polos, sendo um deles instalado no campus Goytacazes do Instituto Federal Fluminense (em uma parceria entre os dois institutos). É importante destacar que a 
oferta foi, inicialmente, como determinado pelo PLAFOR, específica para docentes da rede, sendo descritos no PPC do curso (IFSC, 2014, p. 02) os seguintes requisitos para inscrição e matrícula: “... ser professor em exercício da Carreira do Magistério do Ensino Básico, Técnico e Tecnológico e portador de diploma de curso de graduação (bacharelado ou superior de tecnologia)."

A oferta pode ser vista como uma estratégia para assegurar a formação continuada de docentes não licenciados. Porém, assim como criticado por Machado (2008), caracteriza-se como mais uma ação descontínua, já que não houve, até o momento, continuidade na proposta formativa nos mesmos moldes dessa oferta ${ }^{\mathrm{vi}}$. Outro problema enfrentado foi encontrar no público-alvo o interesse por formações voltadas para a formação pedagógica, ainda mais em uma especialização com 560 horas, com cronograma de 18 meses. O curso iniciou as atividades em dezembro de 2015. Como houve dificuldade de preenchimento das 140 vagas abertas entre docentes, o públicoalvo foi expandido, sendo permitida, com aval da Setec, a participação de técnicos em assuntos educacionais. A questão da falta de interesse em formações continuadas voltadas aos aspectos pedagógicos da docência também foi identificada na pesquisa desenvolvida por Viella e Santos (2015, p. 821):

... os docentes da EPT, embora reconheçam suas limitações para compreenderem os aspectos pedagógicos da docência, não demonstraram interesse em participar de programas de formação pedagógica, considerando que os saberes da experiência e suas vivências são suficientes para sua prática em sala de aula, auxiliando-o a desenvolver seus próprios métodos de ensino, desconsiderando a necessidade de uma formação complementar capaz de proporcionar uma compreensão pedagógica numa dimensão mais ampla, que permita o entendimento das singularidades da educação profissional nos seus mais diversos níveis e modalidades.

Para este estudo, selecionamos, dos integrantes do curso, os matriculados em duas turmas, em princípio totalizando 40 sujeitos. Porém, desses, apenas 26 responderam à atividade aqui em análise. No recorte metodológico, adotado visando atender ao objetivo deste trabalho, que é refletir sobre a formação pedagógica para o exercício da docência, separamos docentes de técnicos-administrativos em Educação, restando-nos um total de 20 sujeitos, sendo eles, considerado o perfil por eles indicado, professores ingressantes nos últimos oito anos (2009 a 2016) no Instituto Federal de Santa Catarina - IFSC. Tomamos como objeto de análise os registros escritos feitos por esses docentes, em uma das atividades desenvolvidas ao longo do curso, na unidade curricular Projeto de Intervenção Pedagógica ${ }^{\text {vii }}$.

\section{Resultados e discussões}

\section{A prática pedagógica nas salas de aula da EPT}

Dos 20 professores cujas vozes são trazidas para este texto, 12 são bacharéis: seis são da área de engenharia (um da mecânica, dois da elétrica, um de controle e automação, dois em civil), dois da Administração, um da arquitetura, um do turismo, 
um química de alimentos e um da agronomia; três vêm de cursos Superiores de Tecnologia (construção de edifícios, produção de usinagem e Alimentos); e cinco são licenciados (dois em Educação Física, um em Geografia, um em Matemática e um em História).

Em relação ao tempo em que estão formados, cinco deles concluíram a graduação na década de 1990 (a graduação mais antiga é de 1994), dez se formaram entre 2000 e 2009 e cinco concluíram a graduação após 2010. Entre o grupo, todos cursaram pós-graduação, seguindo na área da formação inicial, sendo que cinco são especialistas, nove têm mestrado (dois em andamento) e seis têm doutorado. Essas formações foram concluídas recentemente, sendo seis delas entre 2000 e 2009 e os outros 14 após o ano de 2010.

Esses dados da trajetória formativa reforçam a qualificação acadêmica dos profissionais da rede, com percentuais próximos aos identificados por Souza (2014), citados anteriormente. O perfil do grupo em análise também é bem representativo dos números gerais do IFSC. Entre os 1.370 professores efetivos da instituição, 68 são graduados, quatro têm aperfeiçoamento, 168 têm especialização, 702 cursaram Mestrado, 431 o doutorado e dois são pós-doutores (IFSC, 2017) ${ }^{\text {viii }}$.

Os números são bem expressivos, porém, é preciso considerar o que dizem Pimenta e Anastasiou (2002, p. 192), para quem apenas a alta titulação acadêmica não assegura os conhecimentos pedagógicos necessários à docência:

... verifica-se que ser um reconhecido pesquisador, produzindo acréscimos significativos aos quadros teóricos existentes, não é garantia de excelência no desempenho pedagógico.... As sínteses obtidas [com as pesquisas desenvolvidas pelos docentes nos programas de pós-graduação], por via de regra, virão compor programas das disciplinas pelos quais os docentes são responsáveis. Às vezes o programa disciplinar acaba se reduzindo ao tema pesquisado pelo professor, ficando o papel docente reduzido ao repasse e a formação dos alunos, a um rótulo.

Assim como as formações acadêmicas em nível de pós-graduação são recentes, todos os professores ouvidos para a realização deste trabalho ingressaram na carreira da EPT recentemente, sendo que um deles iniciou em 2009, um em 2010, três em 2011, cinco em 2013, dois em 2014, cinco em 2015 e três em 2016. Os dados reforçam que, como já apresentado, a maior parte dos professores da rede entrou na carreira com a expansão gerada a partir de 2008.

Entre o grupo, a maior parte com pouca experiência profissional anterior à entrada na rede como docente (14 dos 20 professores têm menos de cincos anos de experiência profissional anterior, na sua área de formação), a possibilidade de construir uma carreira via concurso público foi uma das principais razões para a entrada para a educação. "Apesar do trabalho desenvolvido atender minhas expectativas profissionais, alguns problemas como a baixa remuneração, questões políticas inerentes ao cargo [que exercia na rede municipal] me fizeram buscar novos horizontes profissionais", afirma o professor (P12), que é engenheiro civil e tinha atuado por dois anos na área, antes de ingressar na rede. 
Mesmo os sujeitos que já atuavam na docência antes de entrar para a rede federal viram em concursos para a área uma oportunidade mais atrativa: “... não via perspectiva de carreira e incentivo à formação, pois tinha que lecionar nos três períodos para poder ter um ganho razoável... Comecei a investigar a carreira de docentes nas redes municipal, estadual e federal. Decidi que faria os concursos que tivesse para matemática", afirma o professor (P18), que tinha 15 anos de experiência profissional quando entrou para a rede federal, em 2015. "Estava no segundo ano do doutorado em Engenharia Elétrica e tinha apenas mais dois anos de bolsa. Comecei a me preocupar em qual seria a minha fonte de renda após o término desses dois anos de bolsa. Então decidi começar a realizar alguns concursos públicos", afirma o professor (P19), que nunca havia atuado profissionalmente na área de formação inicial, quando entrou para a rede, em 2011.

A aprovação em concurso também serviu como atrativo para voltar às cidades de origem, reaproximando-se das famílias, para as hoje professoras da rede (P22) e (P4). "O interesse pelo concurso como docente da ETP também foi movido pelo desejo de retornar para perto dos familiares", afirma a primeira. "Nesse período, surgiu o concurso do IF com várias vagas para Alimentos e tive a certeza de que essa era a minha hora", conta a última.

Também há, entre o grupo, aqueles que ingressaram na carreira por se identificarem com a docência, mesmo não tendo escolhido uma licenciatura à época da formação inicial. "Para mim... foi natural ensinar o que eu já fazia e gostava de fazer.", afirma a professora (P25), cuja experiência anterior como docente se deu em aulas práticas em contratos temporários em cursos profissionalizantes, ministradas para poder se manter na graduação em engenharia. "Posso responder com certeza que minha escolha pela EPT foi devido ao meu perfil técnico e por gostar de compartilhar conhecimento", conclui.

A também engenheira (P14) começou a atuação docente como forma de complementação salarial. A partir daí, “...me apaixonei pela docência. É muito gratificante poder passar a experiência profissional e de vida para pessoas que irão ingressar no mercado de trabalho", afirma a docente ingressante na rede em 2016. "A experiência de transmitir conhecimento e prática para pessoas interessadas na temática me fez, logo cedo, interessar pela docência, mas jamais abdicar do sonho da prática profissional da arquitetura... Até hoje concilio ambas as atuações", afirma a arquiteta (P15), que entrou para a rede em 2015.

Essa possibilidade de ingressar na docência sem uma formação específica na trajetória acadêmica é permitida pela legislação, considerando não haver a exigência de uma licenciatura para a atuação na EPT, muito embora este seja um pré-requisito para o exercício docente em outras modalidades de ensino:

... um problema estrutural do sistema educacional e da própria sociedade brasileira, pois, enquanto para exercer a medicina ou qualquer outra profissão liberal é necessária a correspondente formação profissional, para exercer o magistério, principalmente, o superior ou a denominada educação profissional, não há muito rigor na exigência de formação na correspondente profissão - a de professor. (Moura, 2008, p. 31). 
Carvalho e Souza (2014) também questionam as contradições nas exigências de formação entre Educação Básica Geral e Educação Profissional, sendo a formação em cursos de licenciatura obrigatória na modalidade propedêutica e apenas 'recomendada' na EPT, ou seja:

... os estudos propedêuticos requerem professores com formação teórica e metodológica consistente, fundada em conhecimentos gerais e compreensivos, críticos da realidade, portanto pedagogicamente preparados para a sua condução; enquanto que os estudos profissionais e tecnológicos dispensam os saberes da docência. (Carvalho e Souza, 2014, p. 855).

Independente do motivo inicial que levou diferentes profissionais a se tornarem professores, a docência deve ser assumida como uma profissão e não meramente como um emprego (cf. Pimenta e Anastasiou, 2004), o que passa pela formação continuada que contemple os conhecimentos pedagógicos. Ainda, o perfil de formação diversificado precisa ser levado em conta, ao se pensar em políticas nessa área. É o que reforça Moura (2008, p. 32), ao se debruçar sobre o perfil desses sujeitos:

Uma parte tem graduação específica na área profissional em que atua. São engenheiros, arquitetos, contadores, administradores e outros bacharéis que exercem a docência sem ter formação para tal. Outra parte tem licenciatura voltada para as disciplinas da educação básica, portanto, estão formados para o exercício da docência nesse âmbito, ou seja, para atuar no ensino de matemática, química, geografia, história etc. para estudantes do ensino fundamental ou médio, o que é diferente de atuar, mesmo nessas disciplinas, em cursos cujo fim é a formação profissional. Nesse caso, é fundamental que o docente tenha uma formação específica que lhe aproxime da problemática das relações entre educação e trabalho e do vasto campo da educação profissional e, em particular, da área do curso no qual ele está lecionando ou vai lecionar no sentido de estabelecer as conexões entre essas disciplinas e a formação profissional específica, contribuindo para a diminuição da fragmentação do currículo.

Os profissionais ouvidos durante o desenvolvimento deste trabalho, cada um à sua maneira, sentiram as dificuldades de ingressar na carreira da EPT, seja por não terem formação pedagógica em suas formações iniciais (15 deles), seja por não terem formação para atuar especificamente na Educação Profissional (nenhum eles). Em relação às dificuldades geradas por não terem os conhecimentos pedagógicos na graduação, a professora (P4) afirma: "Sou formada em um curso de bacharelado em Química de Alimentos, sendo assim, não tive formação para ser professora, o que dificulta um pouco a minha atuação"; “... vindo da área técnica não tive em minha faculdade a formação pedagógica", destaca também o engenheiro de Controle e Automação (P6).

Por outro lado, as especificidades da Educação Profissional e Tecnológica impactaram na atuação desses profissionais, ao optarem pela docência. "Eu não era do mercado, eu sempre fui acadêmica e enveredei, por oportunidade, para o ensino técnico. 
Isso me faz enfrentar algumas dificuldades na prática", afirma a professora graduada em Turismo (P20); "Já havia atuado como pesquisadora e docente em cursos superiores em algumas universidades, mas a atuação no IF se mostrou um desafio para mim", afirma a engenheira agrônoma (P22); "Talvez, no primeiro momento, não objetivasse o ensino de EPT, até porque meu conhecimento sobre o tema era escasso. Mas sendo profissional da área técnica (administradora) os caminhos induziam para esta escolha", diz a professora (P3). O ingresso na docência na EPT, como destacam os depoimentos, foi se dando por diferentes razões, tendo como carro-chefe a possibilidade de ingressar em uma carreira com a segurança de um concurso público.

Os professores ouvidos na realização deste trabalho também indicaram terem sentido dificuldades diante do que é uma especificidade da Educação Profissional e Tecnológica e que demanda uma formação pedagógica para a atuação em sala de aula: a heterogeneidade dos públicos atendidos pela rede. A professora (P22) afirma que, já no primeiro semestre em que assumiu como docente, teve que atuar com públicos muitos variados, incluindo alunos de cursos concomitantes e de PROEJA: "Esse desafio é muito complexo, tanto pela diversidade de alunos (adultos, adolescentes, trabalhadores, especiais) quanto pela diversidade de graus de conhecimento."

A questão é também destacada por Viella e Santos (2015, p. 820). As autoras atentam para a heterogeneidade do público-alvo com o qual atuam os docentes na EPT, em relação "... ao desenvolvimento acadêmico, rotina de estudo, recurso financeiro, etnia, cultura, perspectiva em relação ao curso, vida profissional entre outros aspectos da diversidade". Essas questões, salientam as autoras, trazem à tona exigências de formação que "não estão postas com a mesma intensidade em outros níveis e modalidades de ensino". Assim como expresso na fala dos docentes, Carvalho e Souza (2014, p. 888) destacam que:

... esta complexidade na oferta de educação profissional e tecnológica, abrangendo níveis e modalidades distintos, não veio acompanhada de políticas de formação docente. Ao contrário, as discussões atuais acerca da docência para a EPT identificam um histórico de fragmentação, improviso e insuficiência de formação pedagógica na prática de muitos desses professores.

Diante dessa condição, como esses profissionais buscaram suprir as lacunas pela falta de uma formação pedagógica? Do grupo que constitui o corpus deste trabalho, nenhum citou ter recebido formação pedagógica no momento em que ingressou para a rede. Também, nenhum deles disse ter procurado, por conta própria, essa formação. "...busquei suprir as dificuldades por meio de orientações com pedagogos e colegas de trabalho", afirma a professora (P20); "Aplicava métodos de professores que considerava modelos bons de minha formação ${ }^{\mathrm{ix}}$ e pedia muito auxílio à coordenação pedagógica ${ }^{\mathrm{x}}$ de minha unidade", afirma o professor (P2).

Essa busca por conhecimentos próprios da docência de modo individualizado e, muitas vezes, advindo de uma formação mimética, na reprodução de "... métodos de professores que considerava modelos bons de minha formação" (P2), contraria o que defendem os pesquisadores acerca da necessidade de investimentos em uma formação acadêmica voltada à área. Pimenta e Anastasiou (2002, p. 186) destacam: 
A formação do professor, no que se refere aos conhecimentos científicos do seu campo e do campo da Educação, da Pedagogia e da Didática, requer investimentos acadêmicos. Nela se exigirá um ensino que permita ao docente os nexos com o campo e os contextos de produção dos conhecimentos na história e na sociedade. Uma formação que tome o campo social da prática educativa e de ensinar como objeto de análise, de compreensão, de crítica, de proposição, que desenvolva no professor a atitude de pesquisador, como forma de aprender.

Ainda, é fundamental refletir sobre o que apontam Nóvoa e Vieira (2017), quando retomam as diferenças entre os conhecimentos científicos das disciplinas, pedagógico e o conhecimento da profissão docente. Para os eles:

Ser professor não é apenas lidar com o conhecimento, é lidar com o conhecimento em situações de relação humana. Para ser professor não basta conhecer as disciplinas, mais a pedagogia. É preciso adquirir e trabalhar um conhecimento que se encontra no patrimônio da profissão e que necessita de ser valorizado no campo da formação de professores. (Nóvoa e Vieira, 2017, p. 36).

Com isso, os autores defendem a formação específica para a docência, precarizada pelo discurso de que qualquer um "independentemente da sua formação e da sua inserção na profissão, consegue ter bons 'resultados' na escola" (Nóvoa e Vieira, 2017, p. 34 - grifo dos autores).

Percebe-se, pela análise dos depoimentos coletados para este trabalho, as muitas lacunas ainda existentes na formação de professores para a EPT, sobretudo pelas ofertas de formações descontínuas, como a aberta pelo MEC e da qual fizeram parte os sujeitos ouvidos para este trabalho. E mesmo que muitas pesquisas tenham demonstrado o pouco interesse de docentes com alta titulação acadêmica em suas áreas de formação específica em qualificação pedagógica, há a preocupação em atuar de forma a contribuir com a formação dos sujeitos que passam pela Educação Profissional: “... o professor precisa ter a sensibilidade e a sabedoria para direcionar os conhecimentos e adequá-los à área de trabalho em que este atuará posteriormente. É preciso um conhecimento voltado para a EPT", destaca o professor (P21).

Mesmo que as carreiras docentes tenham sido iniciadas pelo atrativo de um concurso público, há vantagens na atuação na docência na EPT que os professores advindos de outras redes apontam: "Realmente, é uma vida totalmente diferente. Nesses dois anos [de atuação na rede] consegui fazer as disciplinas do mestrado, cursos de capacitação e ainda lecionar e participar de todas as atividades do campus e mesmo assim ainda tive tempo para a família. Está sendo um sonho muito bom”, afirma o professor (P18), com trajetória anterior na Educação Básica em outra rede. Essas motivações, entre tantas outras, podem representar as razões que fazem com que esses profissionais continuem exercendo a docência e que, como o grupo aqui em análise, sintam-se mobilizados para uma formação complementar, na perspectiva de aprimoramento dos conhecimentos pedagógicos. 
Como já discutido neste texto, as exigências de formação pedagógica para docentes que atuam na Educação Profissional e Tecnológica têm sido menos rígidas do que aquelas aplicadas à área propedêutica (cf. Carvalho e Souza, 2014, p. 855). A Resolução $\mathrm{n}^{\circ}$ 6, de 20 de setembro de 2012, que define as Diretrizes Curriculares Nacionais para a Educação Profissional Técnica de Nível Médio, traz, como último título do documento, no Artigo 40, as recomendações legais para a formação docente que atua nessa modalidade de ensino. Entre as orientações, embora trate das especificidades de formação acadêmica em nível de graduação e pós-graduação, há uma ampla abertura ao "reconhecimento de saberes profissionais" como uma forma de qualificação para o trabalho docente:

$\S 2^{\circ}$ Aos professores graduados, não licenciados, em efetivo exercício na profissão docente ou aprovados em concurso público, é assegurado o direito de participar ou ter reconhecidos seus saberes profissionais em processos destinados à formação pedagógica ou à certificação da experiência docente, podendo ser considerado equivalente às licenciaturas s:

- I - excepcionalmente, na forma de pós-graduação lato sensu, de caráter pedagógico, sendo o trabalho de conclusão de curso, preferencialmente, projeto de intervenção relativo à prática docente;

- $\quad$ II - excepcionalmente, na forma de reconhecimento total ou parcial dos saberes profissionais de docentes, com mais de 10 (dez) anos de efetivo exercício como professores da Educação Profissional, no âmbito da Rede CERTIFIC;

- $\quad$ III - na forma de uma segunda licenciatura, diversa da sua graduação original, a qual o habilitará ao exercício docente. (Brasil, 2012, p. 12).

O documento aponta como prazo para atendimento do previsto no Artigo 40 o ano de 2020. É preciso, ainda, observar que a formação pedagógica é indicada aos professores em exercício da docência na EPT como um direito, não como uma exigência inerente à profissão docente. Por outro lado, entre o grupo ouvido para o desenvolvimento deste trabalho, que optou pela qualificação pedagógica em nível de especialização lato sensu, identificamos aspectos positivos levantados pelo grupo, ao participarem dessa formação pedagógica:

A contribuição desta especialização para a minha formação tem sido muito grande. A perspectiva inicial tinha sido apenas de atender a legislação [foi informado de que deveria ter formação pedagógica até 2020], mas agora eu estou vendo que a especialização pode melhorar o meu trabalho em sala de aula, dando embasamento teórico sobre os aspectos metodológicos e didáticos. (P19).

Oliveira e Sales (2016, p. 3 - grifos das autoras) classificam essa condição de exigência legal como um “... cenário marcado por muito 'legislamismo' e pouca efetividade". Diante disso, as colocações feitas pelo professor (P19) indicam que, quando movidos pelo desejo de formação em um aspecto específico da atuação docente, que envolve os conhecimentos pedagógicos, os professores se mostram abertos à formação. O professor (P19) reconhece as contribuições da formação para aquilo que é sua meta: ampliar o “... embasamento teórico sobre os aspectos metodológicos e didáticos". 
O professor (P1) também aponta como aspecto positivo a ampliação dos conhecimentos sobre metodologias do ensino, além de destacar a possibilidade de refletir acerca da diversidade do público atendido na EPT: "Acredito que o que mais mudou foi a minha análise crítica diante das metodologias utilizadas... consegui adaptar as metodologias aos diversos públicos devido aos conhecimentos adquiridos sobre currículo e tecnologias educacionais" (P1). É o que também indica como aspecto positivo da formação a professora (P22), para quem "Em termos práticos, a especialização contribui para entender melhor a estruturação didática e pedagógica de uma aula bem preparada, levando em consideração as potencialidades e limitações do público-alvo". A capacidade de refletir sobre as diferentes metodologias, articulando-as às especificidades do público é um dos pontos destacados por Nóvoa e Vieira (2017) como um dos principais aspectos que diferenciam a docência de outras profissões:

A docência não é uma profissão técnica, na qual as soluções são racionais e objetivas. A docência baseia-se sempre numa resposta contextualizada, em situação, diferente de uma sala de aula para outra, diferente de um aluno para outro. Um professor atua sempre num quadro de incerteza, de imprevisibilidade. Muitas vezes não sabemos tudo, não possuímos todos os dados, mas, ainda assim, temos de decidir e agir. Para ser capaz de estar à altura destas exigências, o professor necessita desenvolver disposições reflexivas, que lhe permitam, no momento certo, responder com inteligência e tato a cada situação concreta. (Nóvoa e Vieira, 2017, p. 37).

Nesse cenário, construído a partir do que preconizam os documentos legais, no que apontam as pesquisas realizadas sobre o tema e, também, no que indicam as vozes dos docentes, ao chegar ao final destas páginas que se propõem a refletir sobre o papel da formação pedagógica na carreira docente na EPT, continuamos defendendo essa formação como uma forma de qualificar a prática em sala de aula. Defendemos que esses espaços se constituam em possibilidades de acesso aos conhecimentos pedagógicos e didáticos, além de partilha de conhecimento entre os pares. Dessa forma, como indica a professora (P4): possibilitando “... ampliar meu conhecimento e especialmente refletir de forma crítica minha atuação enquanto docente da EPT, atuando nos diversos níveis de cursos, desde PROEJA, técnico, FIC e superior”.

\section{Considerações finais}

Os processos seletivos de ingresso estudantil na rede Federal de Educação, Ciência e Tecnologia abrem vagas para os alunos e portas para os profissionais que passam a atuar na formação desses. Porém, entrar não basta. Assegurar educação de qualidade e garantir que os estudantes concluam com êxito o curso para o qual se matricularam requer do professor conhecimentos específicos da sua área de formação, mas também o domínio de questões didáticas e pedagógicas, inerentes ao trabalho em sala de aula.

Ouvir os professores que ingressaram na rede nos últimos anos nos possibilitou perceber que a busca por uma carreira via concurso público foi um grande fator de mobilização que levou esses profissionais a chegarem à docência. Ou seja, eles 
“tornaram-se professores", mesmo que a escolha inicial, à época da graduação, tenha passado distante do campo da Educação. Não se afirma, com isso, que os milhares de profissionais que encontraram na docência na EPT uma nova carreira profissional não o façam com competência. A questão que sustenta este artigo parte da defesa pela formação que contemple os conhecimentos da docência e aqueles que tratam das especificidades de ensinar na Educação Profissional, seja como formação inicial ou, no caso daqueles que já atuam na área, na formação continuada.

É preciso, como apontam os autores trazidos para este texto, assegurar aos docentes da rede o "... exercício do magistério como categoria profissional" (Anastasiou e Alves, 2002), a constituição da “... identidade profissional do professor" (André, 2002) e a ampliação dos conhecimentos trazidos por eles das suas graduações em outras áreas, nas quais as questões da docência não estiveram presentes (Moura, 2008).

Não se trata de uma defesa de que todos os docentes da rede que não têm formação pedagógica voltem aos bancos escolares de cursos de graduação ou pósgraduação, mesmo que a experiência aqui descrita aponte para a efetividade dessa ação. Trata-se, porém, da defesa de que as questões didático-pedagógicas façam parte, pelo menos, dos debates em cursos de formação continuada que permitam a partilha e a troca de experiências, tanto do que já foi produzido em pesquisas e estudos sobre o tema, quanto na partilha de práticas entre os pares. Dessa forma, rompendo com um contexto classificado por Nóvoa e Vieira (2017, p. 24) como "individualista" da profissão, já que "Contrariamente a outras profissões, que evoluíram num sentido coletivo - médicos, engenheiros, arquitetos, advogados, etc. -, os professores ainda não encontraram os caminhos da cooperação e da colaboração”. (Nóvoa e Vieira, 2017, p. 24).

Sabe-se de todas as questões que orientam o cotidiano da Educação, incluindo a Educação Profissional e Tecnológica. Por isso, a premissa vale para todos: é preciso assegurar que a formação continuada tenha espaço no cotidiano da escola. Só dessa forma, chegaremos perto do que coloca como meta uma das profissionais da rede ouvidas no percurso deste trabalho e com a qual fechamos o presente artigo: "Deve haver um jeito de garantir vida digna para todos, independente de serem doutores ou trabalhadores braçais" (T13).

\section{Referências}

André, M. E. D. A. (2002). Formação de professores no Brasil - 1990-1998. Brasília: MEC/Inep/Comped.

André, M. E. D. A. (2013). O que é um estudo de caso qualitativo em Educação? Revista da FAEEBA - Educação e Contemporaneidade, 22(40), 95103.

Brasil (2016a). Censo Escolar da Educação Básica 2016: notas estatísticas. Brasília. MEC/INEP. Recuperado em 10 de julho de 2017, de http://download.inep.gov.br/educacao_basica/censo_escolar/notas_estatisticas /2017/.

Brasil (2016b). Nota Técnica $N^{o}$ 67/2016/CGDP/DDR/SETEC/SETEC. Plano de Formação Continuada dos Servidores da Rede Federal - PLAFOR. Recuperado em 28 de setembro de 2017, de 
http://portal.mec.gov.br/index.php?option=com_docman\&view=download\&alia s=40981-nt-67-setec-12maio2016-pdf\&category_slug=maio-2016pdf\&Itemid=30192.

Brasil (2012). Resolução $n^{o}$ 6, de 20 de setembro de 2012. Define as Diretrizes Curriculares Nacionais para a Educação Profissional Técnica de Nível Médio. Brasília: MEC. Recuperado em 27 de novembro de 2017, de http://portal.mec.gov.br/index.php?option=com_docman\&view=download\&alia s=11663-rceb006-12-pdf\&category_slug=setembro-2012-pdf\&Itemid=30192 .

Burnier, S. (2006). A docência na educação profissional. In: Reunião Anual da ANPED, 29, Caxambu. Anais... Caxambu: Anped. Recuperado em 20 de setembro de 2017, de http://29reuniao.anped.org.br/trabalhos/trabalho/GT08-1838 - Int.pdf.

Carvalho, O. F. M., \& Souza, F. H. M. (2014). Formação do docente da Educação Profissional e Tecnológica no Brasil: um diálogo com as faculdades de educação e o curso de pedagogia. Educação e Sociedade, 35(128), 629-996. Recuperado em 22 de setembro de 2017, de http://www.scielo.br/pdf/es/v35n128/0101-7330es-35-128-00883.pdf.

Gatti Bernardete A (2008). Análise das políticas públicas para formação continuada no Brasil, nas últimas décadas. Revista Brasileira de Educação, 13(37), 57-70. Recuperado em 25 de janeiro de 2018, de: http://www.scielo.br/pdf/rbedu/v13n37/06.pdf.

IFSC (2014). Pós-graduação Lato Sensu: especialização em Formação Pedagógica para Docência na Educação Profissional e Tecnológica. Florianópolis: Recuperado em 03 de outubro de 2017, de http://moodle.ead.ifsc.edu.br/pluginfile.php/29042/coursecat/description/PPC.pd f.

Machado, L. (2008). Diferenciais inovadores na formação de professores para a educação profissional. Revista Brasileira da Educação Profissional $e$ Tecnológica, 1(1), 8-22. Recuperado em 22 de setembro de 2017, de http://portal.mec.gov.br/setec/arquivos/pdf3/rev_brasileira.pdf.

Moura, D. (2008). Formação de docentes para a educação profissional e tecnológica. Revista Brasileira de Educação Profissional e Tecnológica, 1(1), 24-38. Recuperado em 22 de setembro de 2017, de http://portal.mec.gov.br/setec/arquivos/pdf3/rev_brasileira.pdf.

Nóvoa, A., \& Vieira, P. (2017). Um alfabeto da formação de professores. Crítica Educativa, 3(2), 21-47. Recuperado em 20 de novembro de 2017, de http://www.criticaeducativa.ufscar.br/index.php/criticaeducativa/article/view/21 $7 / 275$.

Oliveira, R. S., \& Sales, M. A. (2016). Ser professor na Educação Profissional e Tecnológica: fazeres e saberes docentes no IF Sertão-PE. Anais do III Congresso Nacional de Educação, 1(1). Recuperado em 27 de novembro de 2017, de http://www.editorarealize.com.br/revistas/conedu/trabalhos/TRABALHO_EV05 6_MD1_SA4_ID8305_13082016183546.

Pacheco, E. (2008). SETEC/MEC: Bases para uma Política Nacional de EPT. Recuperado em 10 de julho de 2017, de http://portal.mec.gov.br/setec/arquivos/pdf2/artigos_bases.pdf. 
Pasquali, R., Vieira, J., \& Vieira, M. (2015). Formação de professores para a Educação Profissional e Tecnológica a distância da Rede Federal de Educação Brasileira: análise das produções acadêmicas. Revista Brasileira da Educação Profissional Tecnológica, 9 (2), 22-31. Recuperado em 25 de janeiro de 2018, de http://www2.ifrn.edu.br/ojs/index.php/RBEPT/article/view/3558/1261.

Pimenta, S.G., \& Lea das Graças, A. (2002). Docência no ensino superior. São Paulo: Cortez.

Severino, A. J. (2007). Metodologia do Trabalho Científico. 23ª ed. São Paulo: Cortez.

Viella, M. A., \& Santos, F. B. (2015). A formação de professores para a Educação Profissional e Tecnológica no quadro das pesquisas sobre formação de professores. In.: Encontro Internacional Trabalho e Formação de Trabalhadores, 4., nov. 2015, Fortaleza. Anais. Fortaleza: UFC; IFCE. Recuperado em 27 de setembro de 2017, de http://docs.wixstatic.com/ugd/d70b51_244826293e51422d90a2c55c13937f63.pd f.

\footnotetext{
' Pós-Doutoranda no Programa de Pós-Graduação em Educação da Universidade do Estado de Santa Catarina - UDESC. Bolsista PNPD - CAPES.
}

ii O depoimento do professor faz parte dos dados em análise de uma pesquisa em desenvolvimento de estágio de pós-doutorado no PPGE/UDESC, financiado pela Capes, via bolsa PNPD. Para preservar a identidade dos sujeitos cujas vozes são trazidas para este texto, eles são nomeados como P (Professor), seguido do número que indica a sequência de catalogação dos depoimentos. Como, ao longo da constituição do corpus de análise, também foram catalogados depoimentos de Técnicos-administrativos em Educação-TAEs, a numeração que identifica os sujeitos ultrapassa o número 20, total de docentes ouvidos neste trabalho.

iii De acordo com o Censo Escolar da Educação Básica 2016 (BRASIL, 2016a), a expansão da rede EPT assegurou, em 2016, mais de 1,9 milhão de matrículas só em ofertas integradas à Educação Básica.

iv A servidora atua como Assistente de Aluno (cargo técnico na rede, por isso aqui representado pela letra T). Os depoimentos de técnicos-administrativos em educação da rede EPT fazem parte de coleta de dados adicionais desta pesquisa, que está focada na constituição da carreira docente. De qualquer modo, é importante lembrar o também expressivo número de vagas abertas nos últimos anos para a carreira, atraindo profissionais licenciados, mas também graduados em diferentes áreas, como Direito, Serviço Social, Administração, no caso dos profissionais ouvidos nesta pesquisa, entre outros. Como mostram os números aqui já apresentados, hoje são 28.262 técnico-administravos em educação atuando na rede EPT (BRASIL, 2016b).

${ }^{v}$ A própria oferta aqui em análise e a ser descrita com mais detalhes na sequência confirma esses dados, já que a Especialização em Formação Pedagógica para a Docência em EPT, aberta pela Setec/MEC em 2015, caracterizou-se como uma oferta única da referida Secretaria, embora a Política Nacional da EPT aponte para essas formações como ações a serem desenvolvidas para assegurar a formação pedagógica dos docentes da rede.

${ }^{\text {vi }}$ No caso aqui em análise, o instituto bancou uma oferta própria da especialização em Docência para EPT, já que a SETEC não sinalizou para nova oferta de turmas.

vii A atividade foi aplicada no semestre 2016-2. Os pós-graduandos deveriam responder, em atividade presencial aplicada nos cinco polos de realização da oferta, a uma questão aberta, na qual questionava-se: - como foi a sua escolha pela atuação na EPT (como docente ou como técnico)? qual foi a contribuição desta especialização para a sua formação para a docência na EPT?

viii Relatório disponível no sistema Intranet da instituição, em: https://sipac.ifsc.edu.br/sigrh/public/home.jsf. Acesso em 27 out. 2017.

ix Ao discutir a reprodução dos fazeres dos docentes no futuro exercício profissional de estudantes de licenciatura, Nóvoa e Vieira (2017, p. 22) afirmam que: "Todos sabemos, há muito tempo, que os 
estudantes das licenciaturas nunca fazem, mais tarde, aquilo que lhes dizemos para fazerem, mas aquilo que com eles fizermos durante a formação. É a consciência desta realidade que nos deve levar a uma procura de coerência na forma como construímos os programas de formação de professores".

${ }^{\mathrm{x}}$ Embora esta tenha sido a única referência feita pelos docentes ouvidos neste trabalho acerca da atuação das coordenações pedagógicas junto aos docentes, é importante destacar que essas coordenações estão presentes em todas as unidades da rede. Ainda, é necessário destacar o que apontam Nóvoa e Vieira (2017, p. 15), para quem a existência, no Brasil, do coordenador pedagógico, “... pode, e deve, cumprir uma função importante na formação continuada. Não se trata de multiplicar reuniões administrativas, pesadas e sem sentido, mas de construir momentos de troca e de partilha inspiradores e formadores. A prática, por si só, de pouco serve. Mas a prática refletida, pensada, trabalhada teoricamente, é a mais relevante matéria-prima da formação continuada".

Data de recebimento: $15 / 02 / 2018$

Data da revisão: 19/03/2018

Data do aceite: $27 / 03 / 2018$ 